ESSAY

\title{
Zen and the art of painting
}

I have always been the scientific one in a family of artists: actors, painters and illustrators. As a child I was sent for art lessons with my sister, who is now an illustrator, but I was too self-conscious to express myself artistically. And if I did dare to pick up a paintbrush, my father would look at the results and say "Don't give up your day job!"

And so, I am a hematologist: a clinician, a laboratory physician and a teacher. I am also a wife and the mother of three children. I have a full life, and yet, in 2003, when a friend, showed me The Artist's Way, a program for blocked artists that she was following, ${ }^{1}$ I decided to try it. The program consists of stream-of-consciousness journaling called morning pages, and artist dates: time spent alone doing something concerning the arts. I persisted, even though I felt like a pretender.

What came back to me in the morning pages was an image from more than 20 years before. At that time my husband Hendrik and I seemed unable to start a family. This was a very stressful time and at a certain point, I became depressed and unable to go on with the investigations for infertility. I ended up in analysis, during which I formed an image of myself, desolate and alone in a boat on a lake. In my mind I named it "The Desolation of Infertility." During my artist dates, I started looking for that image in art books and at galleries, but I couldn't find what I had in mind. Finally, I decided to paint it myself. I took out an old children's paint box, a paintbrush and some sketching paper, and painted a primitive version of what I had in my mind.

$\stackrel{m}{q}$ Having done that, I was surprised to see that the image, which had been static for more than 20 years, started moving on in my mind. The boat moved "Into the Shallows." The person in the boat got out and started "Climbing the Mountain." The shoes, representing the

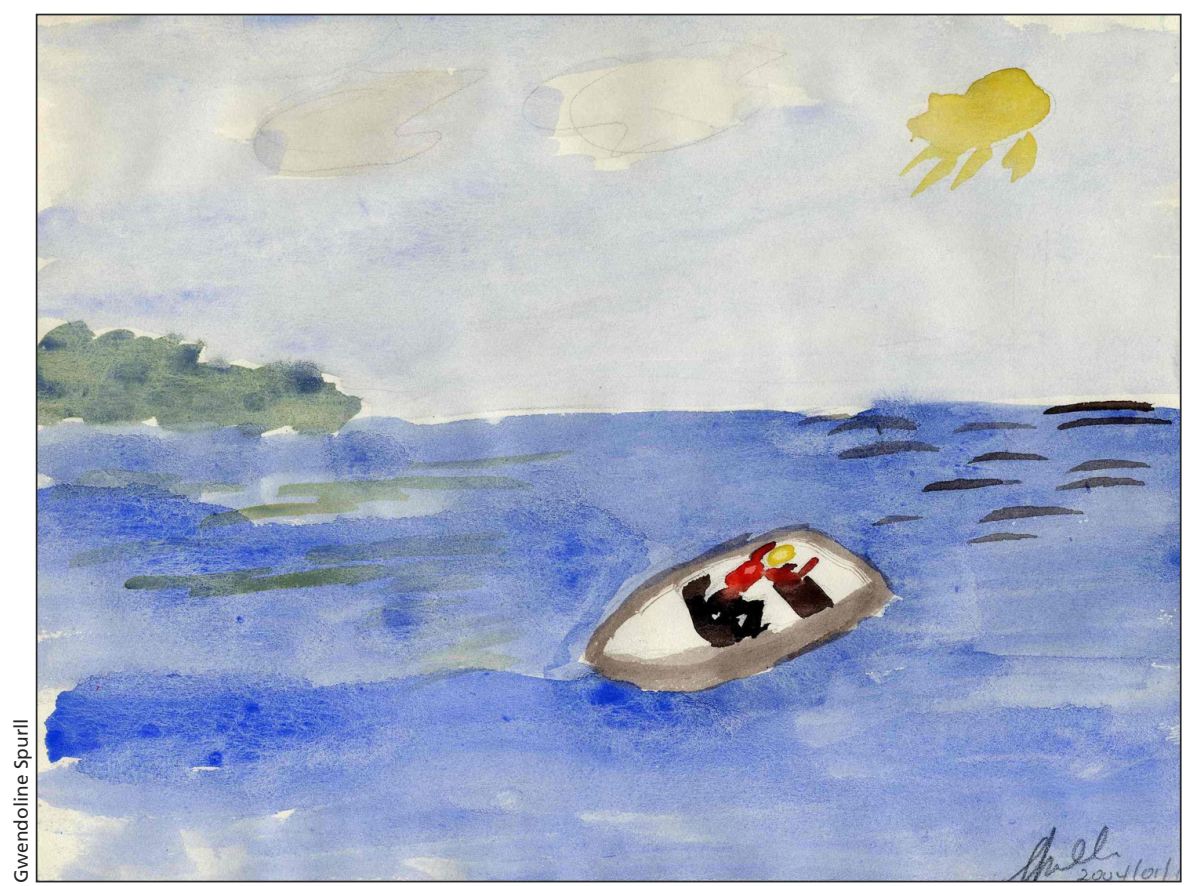

"The Desolation of Infertility" (2004). Watercolour on paper. $28 \times 21 \mathrm{~cm}$. Collection of the artist.

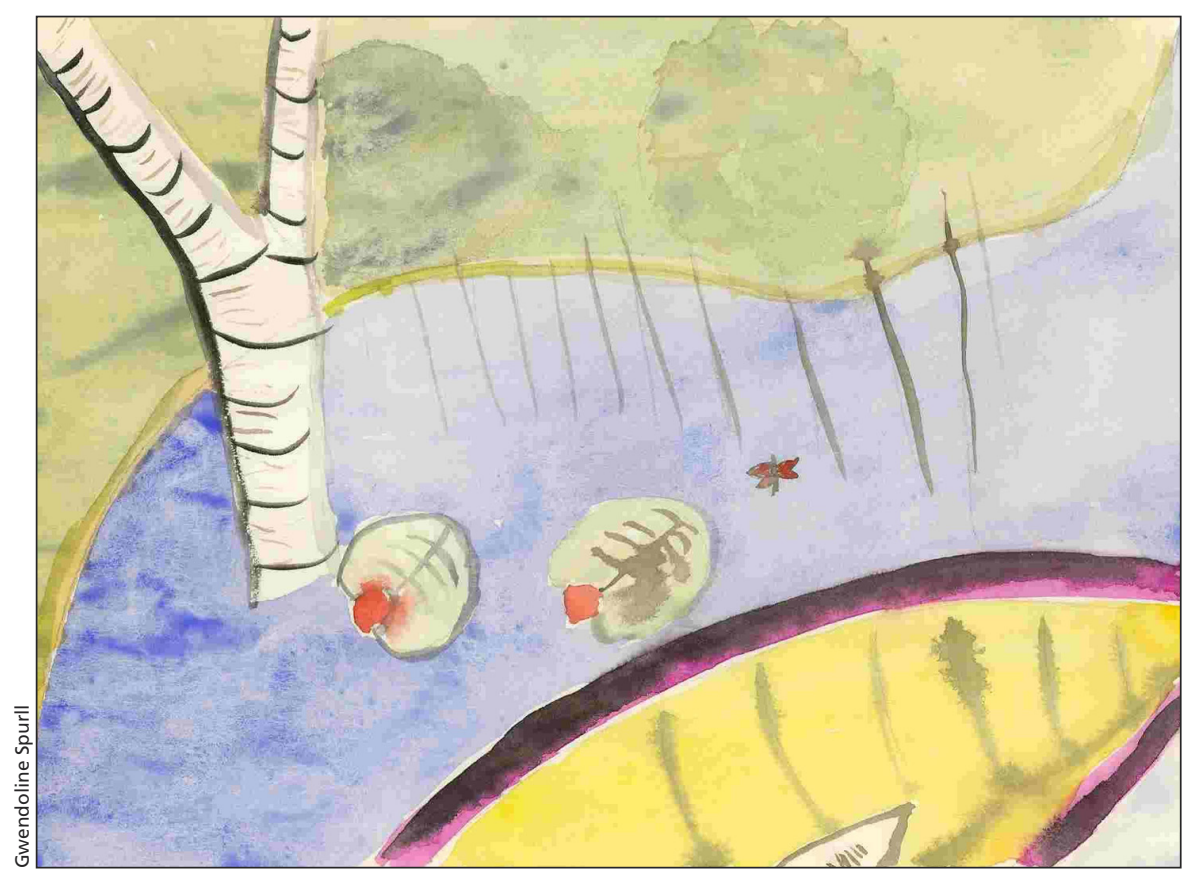

"Into the Shallows" (2004). Watercolour on paper. $28 \times 21 \mathrm{~cm}$. Collection of the artist. 


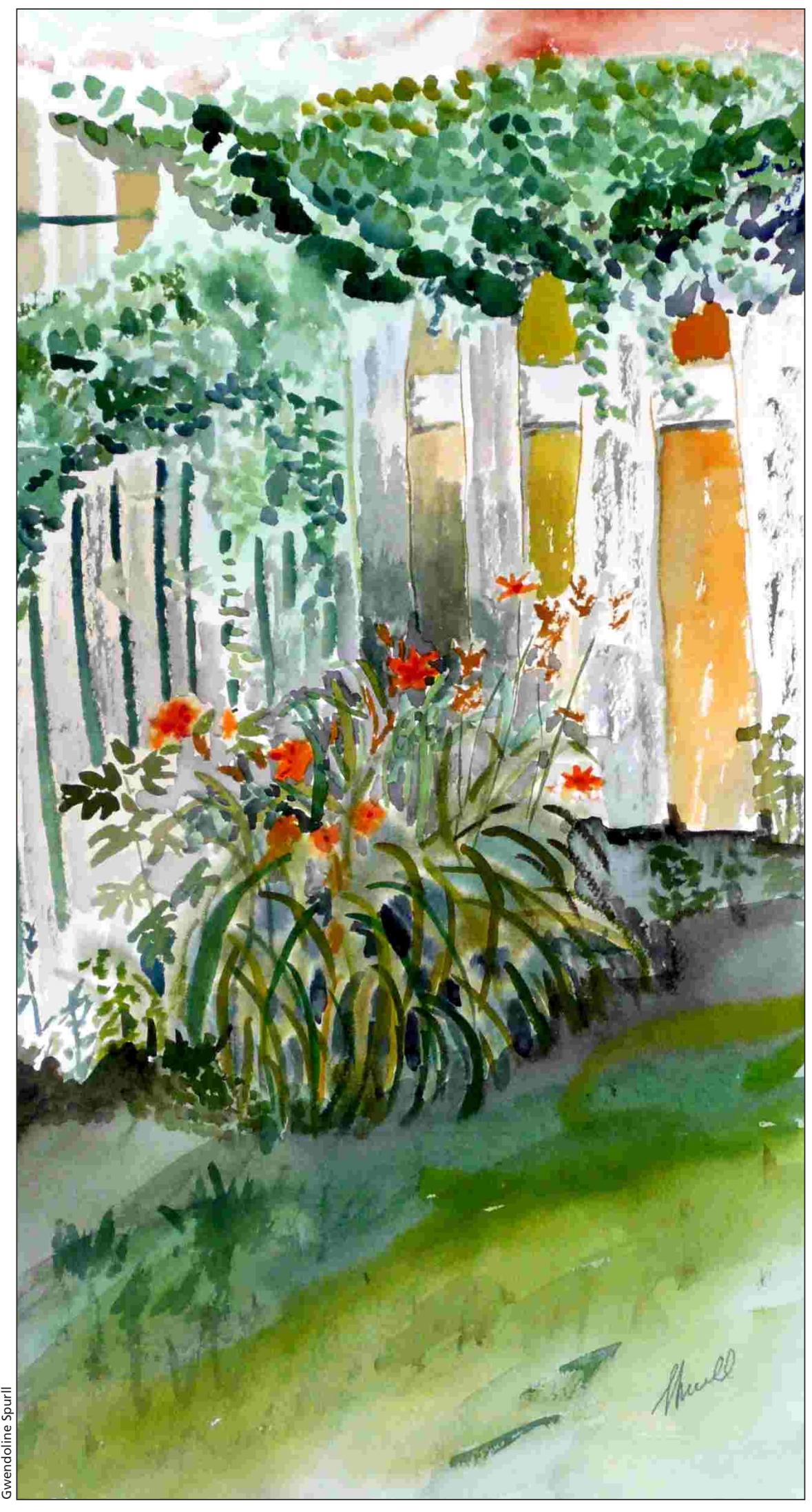

"Day Lilies" (2008). Watercolour on paper. $28 \times 42 \mathrm{~cm}$. Collection of the artist. The artist states that the Day Lily series captures "the wild beauty of my garden, with flowers growing in spite of the fact I can no longer care for them."

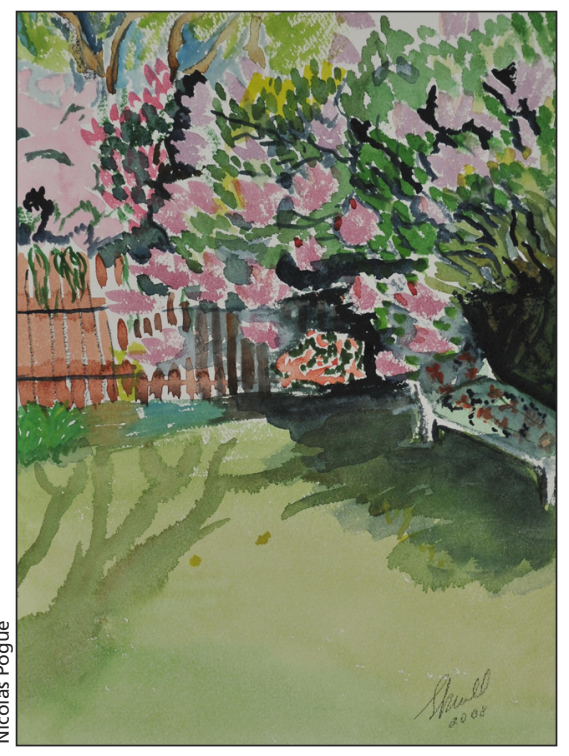

"Garden Retreat" (2008). Watercolour on paper. $28 \times 42 \mathrm{~cm}$. Collection of the artist. According to the artist: "This painting shows a part of my garden where I can hide in the shade, under the badly overgrown lilacs."

path walked, and the pack, representing the burden, were left behind ("View from Above"). What I ended up with over the next weeks was a series of paintings depicting this transition.

Did the journeyer reach the top of the mountain, or did she just discover there were more heights to climb? I don't know. But I did know that if I was going to paint, I should learn the techniques, so I took a drawing class, then a painting class. Painting became an important part of my life. As my daughter said in one of her college applications "My mother is a part-time painter."

Then, in 2005, I developed some strange symptoms. It began in February as I was walking across Sears, shopping for clothes with one of my children. I felt my left foot grip the floor, like a grasp reflex, but in the foot rather than in the hand. I asked my doctor about it, and she said that sort of symptom could only be explained by something in the central nervous system, and that seemed a little unlikely. After consulting a neurologist, she told me it was probably just nerves.

In May, I noticed that my left arm was not swinging as I walked. My movements were slowed and my left 
arm took a fixed position when I was not actually using it. When I told Hendrik, he said "Well you have to hold it somehow."

Then there were small involuntary movements of the fingers of my left hand, particularly when I was nervous.

And I fell. That was what people noticed the most.

I thought I had a brain tumour and waited to have seizures (terrifying, since my husband's first wife had died of an epileptic seizure).

Finally, when the symptoms were no better after a holiday, my friend insisted I see my doctor again and that I see a neurologist. The diagnosis of Parkinson disease was made. I started on medication, which has helped a lot, but I have still had to make a lot of changes in my life, mainly to the pace of my work life. Painting allows me to express how I feel about what is going on.

A series called Broken Hallelujah (the title courtesy of Leonard Cohen) began after the art teacher asked us to bring something to class to paint. I brought a prism and used the image of broken light to capture the joy and dismay that I feel in my present life: joy, that I can continue to do many things, including working and painting; dismay, that I so easily reach my physical limits and have to rest or do something nonphysical.

Later pictures, such as "The Storm," express the regret I anticipate feeling when I eventually have to leave my home because I can no longer manage the stairs. I painted “The Storm" over the Christmas period in 2007, during a snowstorm that kept me housebound. It shows the view from my front windows as

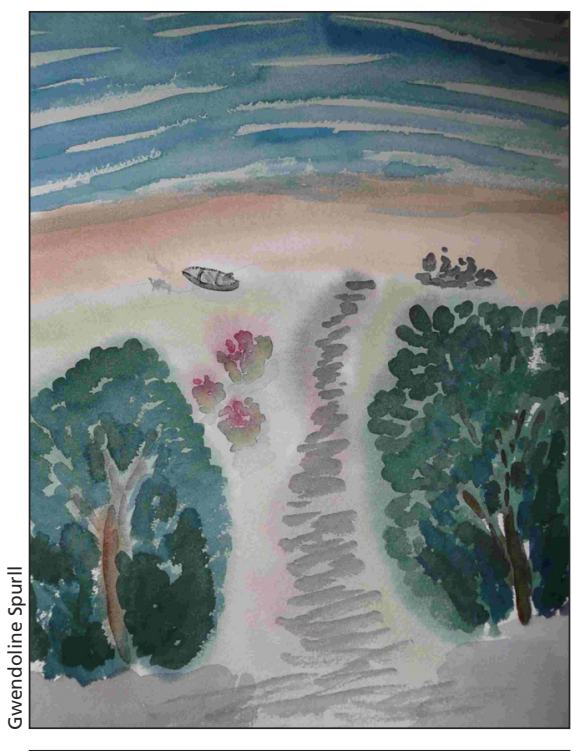

"View from Above" (2005). Watercolour on paper. $25 \times 30 \mathrm{~cm}$. Collection of the artist.

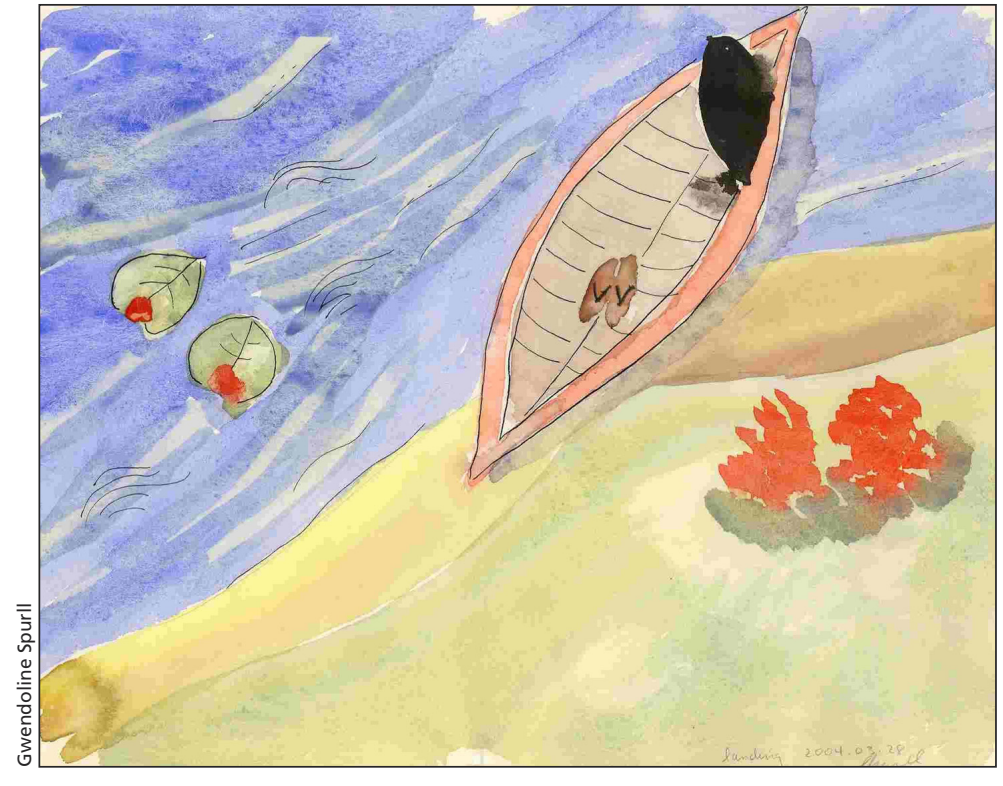

"Climbing the Mountain" (2004). Watercolour on paper. $28 \times 21 \mathrm{~cm}$. Collection of the artist.

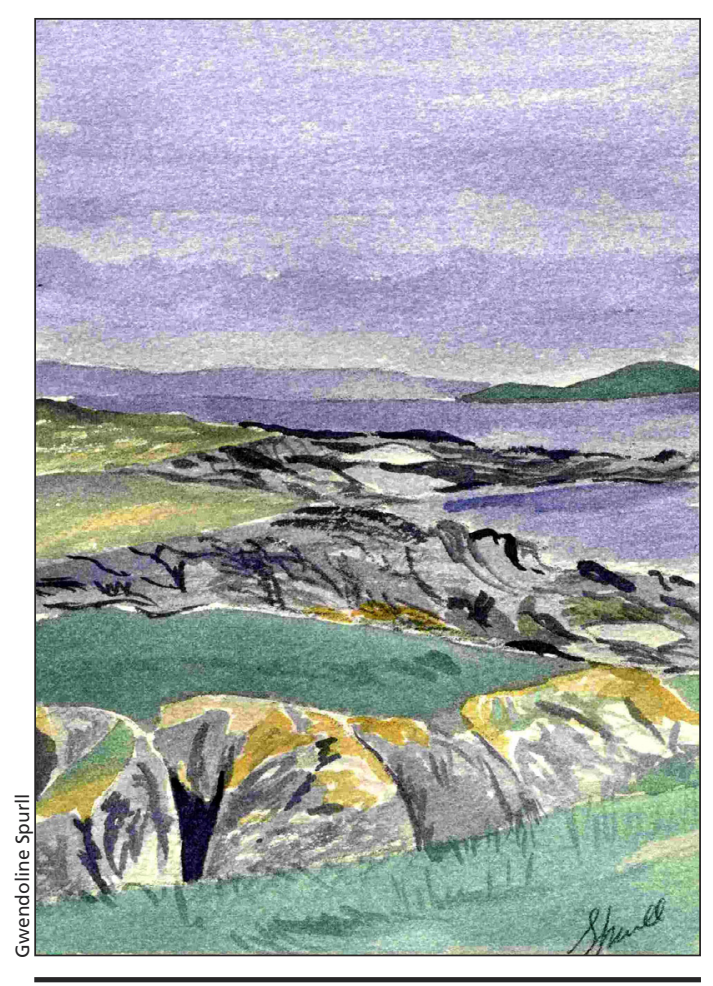

"Iona" (2007). Watercolour on paper. $25 \times 30 \mathrm{~cm}$ Destroyed in a fire. 


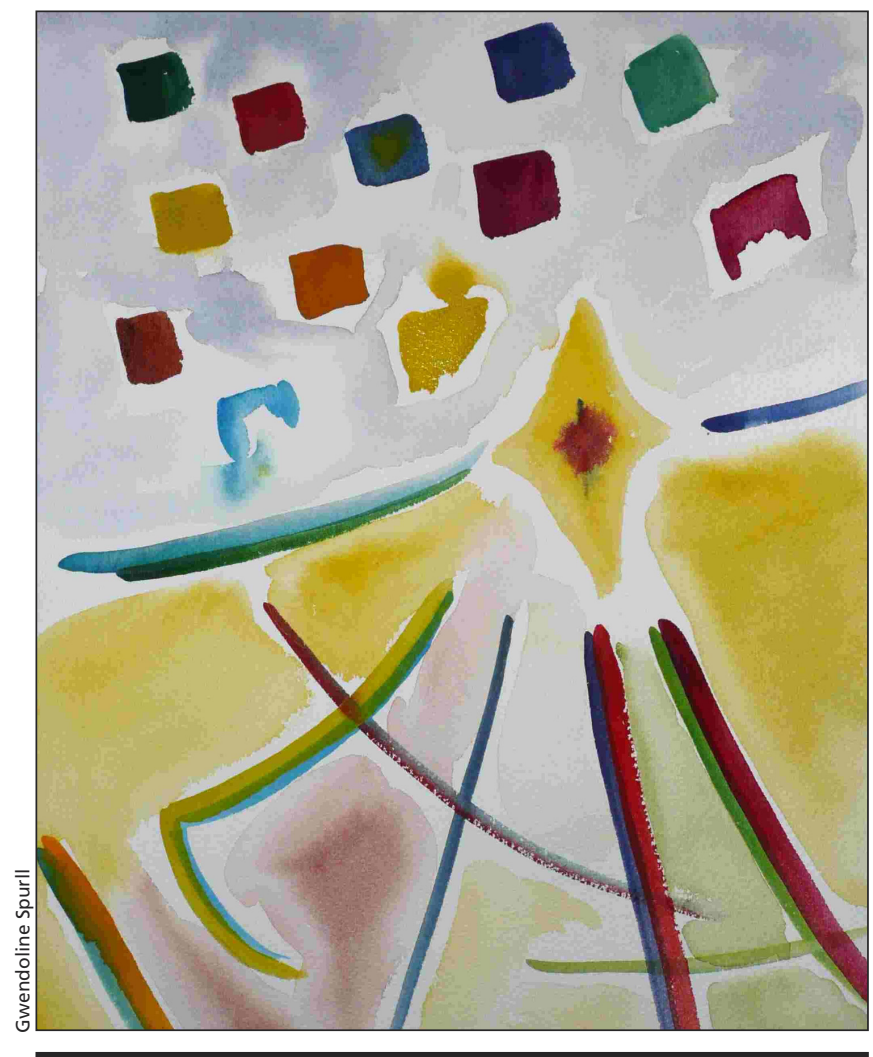

"Broken Hallelujah" (2007). Watercolour on paper. $25 \times 30 \mathrm{~cm}$. Collection of Barbara Spurll. snow falls silently, my familiar plants framing my neighbours' homes. In 2007, I also visited a medical school friend living on a lake in Minneapolis, Minnesota and I did a series entitled, Lake Harriet, depicting the peace of the area. These paintings are described by anyone who sees them as Zen.

Does painting affect my practice as a physician? I think so. My patients often describe my bedside manner as "calm, even Zen." They have told me they come into the examining room agitated, but leave 10 minutes later feeling as though they had spent six hours meditating. I find that sitting down with a blank piece of paper and paints induces a calm state in my mind that removes me from the imperfections of my life - and it convinces me that patients can likewise accept whatever confronts them. Apparently, this conviction is communicated to my patients through my calmness.

My artistic efforts have had other unexpected spinoffs. I used paintings to illustrate my application for a promotion. In my presentation I illustrated the workplace as it was, with cloudy skies ("Angry Clouds"), and how I felt it should be ("The Sunset"). One of the interviewers was so inspired that he has since taken up photography again.

I also participated in a watercolour show in Montréal this fall ("Dix Coups de Pinceaux," at the Mile End Gallery) which was favourably reviewed in the Montreal Gazette. ${ }^{2}$

And now the question comes to me: Is it a coincidence that I started painting so close in time to the onset of symptoms of Parkinson disease? Maybe not.

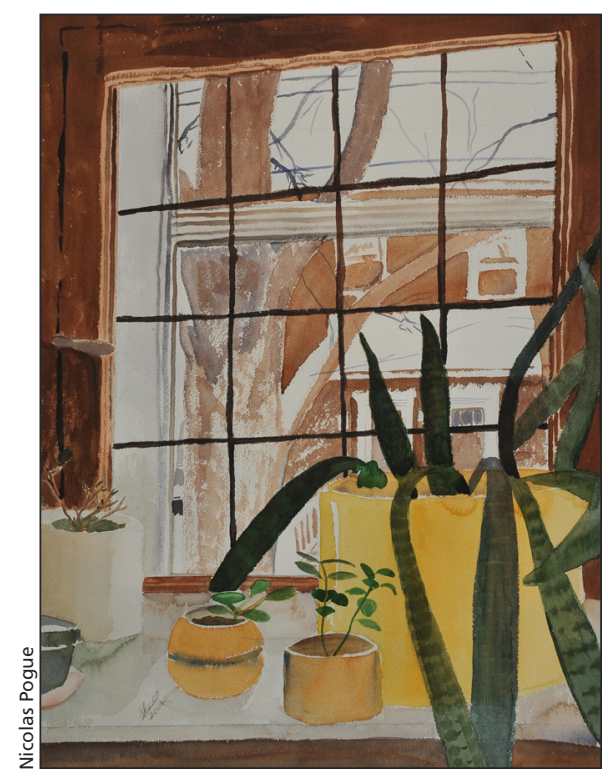

"The Storm" (2007). Watercolour on paper. $56 \times 84 \mathrm{~cm}$. Collection of Therese Weinberger.

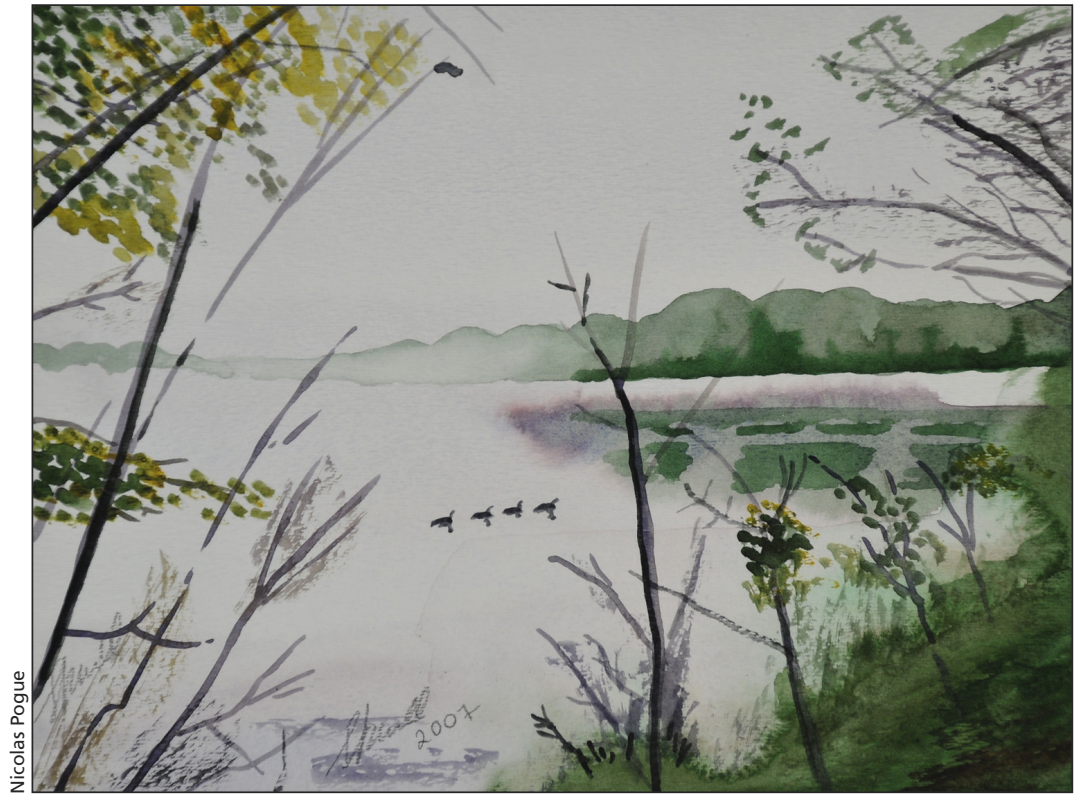

"Lake Harriet" (2008). Watercolour on paper. $30 \times 25 \mathrm{~cm}$. Collection of Kathy Riches. 
In the opening chapter to Musicophilia, Oliver Sacks describes the unexpected sudden onset of creativity in patients with neurological defects. ${ }^{3}$ It seems there is a region in the frontal lobe that inhibits self-expression, and lesions in that area can free it up. In another example, Anne Adams, a scientist who took up painting during a hiatus in her work life, may have done so as a first sign of frontotemporal dementia.

So perhaps the painting presaged the Parkinson.

What does this mean? I don't know. But one can only follow where the path leads, whether it goes to the top of the mountain or not.

I do know that there are only two times when I forget about the Parkinson disease: when I am solving a difficult clinical case, and when I am painting. And painting gives me a focus in my life other than medicine that I hope will continue when I am no longer physically capable of practising medicine. It induces a flow state, and removes from my consciousness the constant knowledge of my physical limitations. It is like a meditation. It is my Zen.

\section{Gwendoline M. Spurll MD}

Hematologist

McGill University

Montréal, Que.

\section{REFERENCES}

1. Cameron J. The artist's way: A spiritual path to higher creativity. Los Angeles (CA): Jeremy P. Tarcher/Perigee; 1992.

2. Boone M. Amateur artists turn pro with watercolour exhibit at Mile End Gallery. The Montreal Gazette 2008 Sept. 29; Sect A:7.

3. Sacks O. Musicophilia: tales of music and the brain. New York (NY): Alfred A. Knopf; 2007.

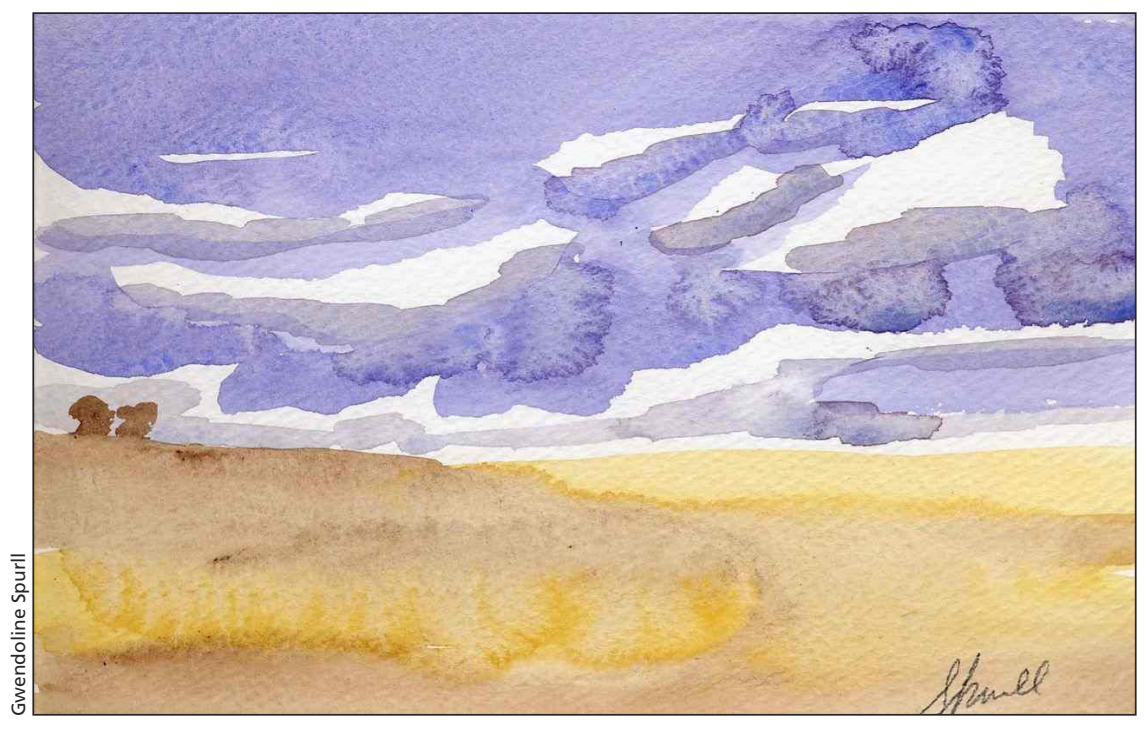

"Angry Clouds" (2005). Watercolour on paper. $23 \times 15 \mathrm{~cm}$. Collection of the artist.

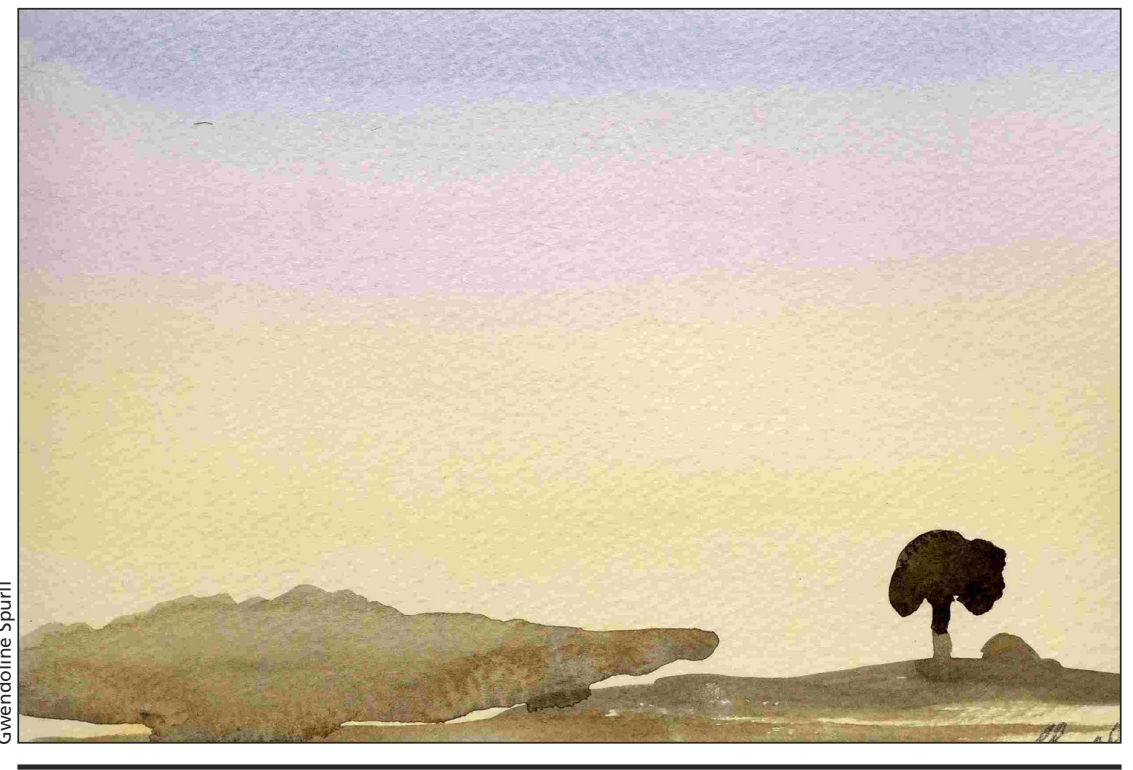

"The Sunset" (2005). Watercolour on paper. $15 \times 23 \mathrm{~cm}$. Collection of the artist. 